\title{
Influence of External Factors on Airborne Missile's Horizontal Backward Launching
}

\author{
Xiao Pan (D, Yi Jiang, Dong Hu, and Huihui Guan \\ School of Aerospace Engineering, Beijing Institute of Technology, Beijing 100081, China \\ Correspondence should be addressed to Xiao Pan; panxiao0@outlook.com
}

Received 19 May 2021; Accepted 11 August 2021; Published 24 August 2021

Academic Editor: Jinyang Xu

Copyright (C) 2021 Xiao Pan et al. This is an open access article distributed under the Creative Commons Attribution License, which permits unrestricted use, distribution, and reproduction in any medium, provided the original work is properly cited.

\begin{abstract}
This paper studies the influence of different external disturbance factors on the horizontal backward separation of airborne missiles on large transport aircraft. The method of comparison with experiment was adopted to verify the accuracy of the finite element model during the ejection process. By comparing the finite element model, it was confirmed that the all rigid body model and partly rigid body model are inaccurate in calculating the pitch angle and pitch velocity of the missile separation. Finally, the influences of ejection force, random vibration, and missile loading position on the ejection process are analyzed. The analysis found that the ejection force and the sliding distance will increase the vibration of the launching platform, therefore increase the separation pitch angle and the pitch velocity of the missile, but the influence of random vibration on platform is much greater than the other two factors, and it will also introduce randomness into the movement of the missile.
\end{abstract}

\section{Introduction}

The airborne missile horizontal backward launching is a method to launch missiles using large transport aircraft. The missiles are stored and transported in a large transport aircraft and ejected horizontal backward at predetermined position. This new launching method is gathering attention more than ever in military, owing to its huge advantages such as greater missile loading capability and wider range of operational missions [1]. Today, the dynamic properties of large transport aircraft have been deeply analyzed and understood; however, the way to establish a mature and safe missile launching platform in the cabin of the large transport aircraft is still under research. Moreover, the influence of the transport aircraft's own motion characteristics, such as cabin vibration during flight, and the properties of the launching platform, such as ejection forces and missile position, on the launch process is also in urgent need of analysis. Figure 1 shows a conceptual diagram of an airborne missile launching horizontally and backwards.

A large and growing body of researches has investigated on the ejecting and separation process between the missile and aircraft. Lee et al. [2] present a unified high-fidelity flight dynamic modeling technique for compound aircraft. This technique can be used to calculate the kinetic response of a new aircraft before the wind tunnel experiment. Surace and Pandolfi [3] demonstrated the vibration attributes of the missile under the continuous random vibration impact from the environment using finite element methods. Liao et al. [4] researched the launch dynamics of oriented-rail launch technique for airborne missile and analyzed the external influencing factors of it, including pneumatic force, launch obliquity, slide length, and others. Wang et al. [5] studied the vibration characteristics, dynamics response of a launching system, and the initial disturbances of the missile. Ma et al. [6] proposed a parameter estimation method that can calculate nonlinear vibration characteristics of missiles during exercise. Zhou et al. [7] proposed an analytical method to directly obtain the aeroelastic time domain response of the elastic boundary panel. Pan et al. [8] carried out a number of investigations into the effect of continuous gusts on the initial disturbance of the airborne missile's horizontal backward derailment on large transport aircraft. 


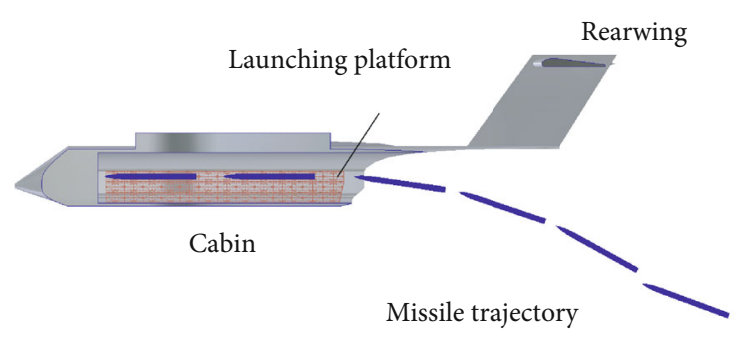

Figure 1: Horizontal backward launching.

For the separation study of missile carriers, most focused on the missile separation process of the fighter. Schindel [9] systematically introduced and analyzed a problem for safe, repeatable, and predictable separation of stores from aircraft; described the impact of the stores on the aircraft; and proposed the safety separation criteria for the separation of the external objects from the carrier. Covert [10] established the relationship between initial conditions of missile separation and the flight path, then proposed a criterion for judging safety separation. Wang et al. [11] investigated a fluid model considering pneumatic and external interference, which can simulate kinetic response during the process of separation. Chen et al. [12] proposed a simulation method that can calculate the separation of the missileadapter mechanism quickly and accurately under different external environment. Vasconcelos and Leite [13] developed and verified a new set of onboard optical trajectory systems for real-time analysis of separation trajectories in three-dimensional space. Zhao et al. [1] researched a missile separation model in the open state of the aircraft, and the changes in missile force and posture were studied. In addition, Xu et al. [14] calculated the impact of the different initial attack angle on the movement of the missile in the high-altitude environment. Qiu and Ang [15] studied the impact of attributes on the connection position on the aircraft load.

For this new type of launching method, previous researches often focused on the verification of the calculation models and the study of individual influencing factors. There are few researches on the comparison of the influence of various external factors and the decision-making of the specific ejection force and ejection position in the ejection process. In order to verify the dynamic characteristics of the launch mechanism and provide a reference for structural design and layout, it is necessary to establish a set of reasonable calculation models, analyze the law of the missile movement of the launch structure, and analyze the effect of various influencing factors on the separation movement of the missile.

In this paper, the finite element method, multibody dynamics, and launch dynamics are used to carry out modeling analysis on dynamic process of missile's horizontal backward separation. The credibility of the simplified model and the impact of the external factors on the ejection process are discussed at the same time. It provides a theoretical basis and reference for the design and optimization of airborne missile horizontal backward launching system.

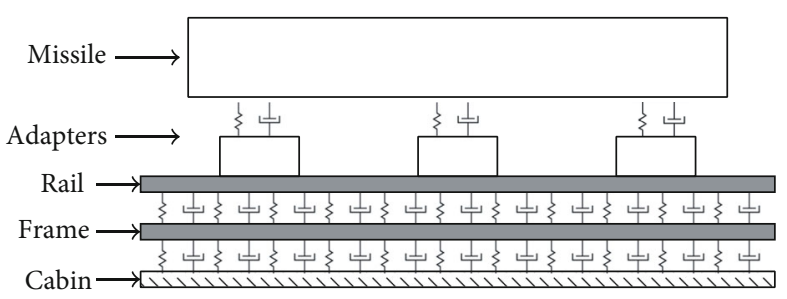

Figure 2: Missile-adapter-rails-frame coupling model.

\section{Theory}

In order to analyze the influence of external factors on the backward launching system, it is necessary to analyze the power spectral density characteristics of the system itself. The simplify coupling model of the missile-adapter-railsframe structure is shown in Figure 2. The whole structure can be treated as a launching platform, which includes missile, adapters, rails, frames, and cabin, and can be considered as a multirigid body system connected by springs and dampers. The contact between the adapter and the track is simplified as linear Hertz elastic contact, the rails are simplified to Euler beams, and the frame is simplified to beams with uniform mass distribution along the track direction. The uniformly distributed linear springs and dampers are used to simulate the stiffness and damping relationship between different parts.

Considering the effects of viscous damping and strain damping [16], the vibration differential equation of the missile-adapter-rails-frame system can be established as equations (1)-(3):

$$
\begin{aligned}
& E_{r} I_{r} \frac{\partial^{4} z_{r}(x, t)}{\partial x^{4}}+m_{r} \frac{\partial^{2} z_{r}(x, t)}{\partial t^{2}}+c_{r e} \frac{\partial z_{r}(x, t)}{\partial t} \\
& \quad+c_{r i} I_{r} \frac{\partial^{5} z_{r}(x, t)}{\partial x^{4} \partial t}+k_{p}\left[z_{r}(x, t)-z_{s}(x, t)\right] \\
& \quad+c_{p}\left[\frac{\partial z_{r}(x, t)}{\partial t}-\frac{\partial z_{s}(x, t)}{\partial t}\right]=\sum_{l=1}^{3 N} F_{l} \delta\left(x-v t-p_{l}\right),
\end{aligned}
$$

$$
\begin{gathered}
E_{s} I_{s} \frac{\partial^{4} z_{s}(x, t)}{\partial x^{4}}+m_{s} \frac{\partial^{2} z_{s}(x, t)}{\partial t^{2}}+c_{s e} \frac{\partial z_{s}(x, t)}{\partial t}+c_{s i} I_{s} \frac{\partial^{5} z_{s}(x, t)}{\partial x^{4} \partial t} \\
-k_{p}\left[z_{r}(x, t)-z_{s}(x, t)\right]-c_{p}\left[\frac{\partial z_{r}(x, t)}{\partial t}-\frac{\partial z_{s}(x, t)}{\partial t}\right] \\
+k_{m}\left[z_{s}(x, t)-z_{d}(x, t)\right]+c_{m}\left[\frac{\partial z_{s}(x, t)}{\partial t}-\frac{\partial z_{d}(x, t)}{\partial t}\right]=0,
\end{gathered}
$$

$$
\begin{aligned}
E_{d} I_{d} & \frac{\partial^{4} z_{d}(x, t)}{\partial x^{4}}+m_{d} \frac{\partial^{2} z_{d}(x, t)}{\partial t^{2}}+c_{d e} \frac{\partial z_{d}(x, t)}{\partial t} \\
& +c_{d i} I_{d} \frac{\partial^{5} z_{d}(x, t)}{\partial x^{4} \partial t}-k_{m}\left[z_{s}(x, t)-z_{d}(x, t)\right] \\
& \quad-c_{m}\left[\frac{\partial_{s}(x, t)}{\partial t}-\frac{\partial z_{d}(x, t)}{\partial t}\right]+k_{c} z_{d}(x, t)+c_{c} \frac{\partial z_{d}(x, t)}{\partial t}=0 .
\end{aligned}
$$


Missile

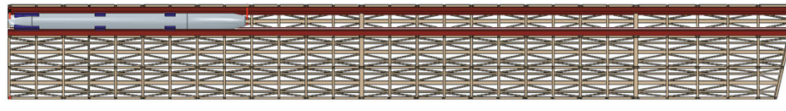

Figure 3: Launching platform and missile.

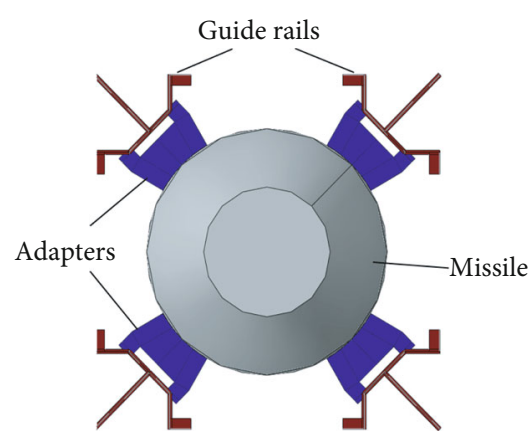

Figure 4: Missile, adapters, and guide rails.

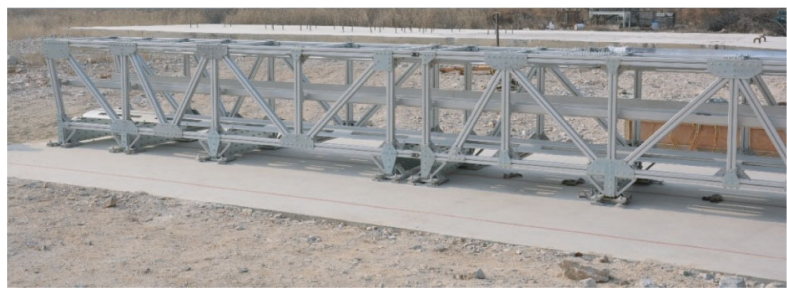

FIGURE 5: Missile-carrying unit of a set of racks.

$E_{r}, E_{s}$, and $E_{d}$ are the elastic modulus of rails, frame, and support surface in the cabin; $I_{r}, I_{s}$, and $I_{d}$ are the horizontal moments of inertia of these three parts; $m_{r}, m_{s}$, and $m_{d}$ are the mass per unit length; $z_{r}, z_{s}$, and $z_{d}$ are the vertical deflection; $c_{r e}, c_{r i}, c_{s e}, c_{s i}, c_{d e}$, and $c_{d i}$ are the viscous damping and strain resistance coefficient; $k_{p}, k_{m}$, and $k_{c}$ and $c_{p}, c_{m}$, and $c_{c}$ are the stiffness and damping between adapter-rails-framecabin system; $F_{l}$ is the dynamic interaction force of the $l$ th group of adapters caused by the rails, $v$ is the sliding speed of the missile, $p_{l}$ is the distance between the $l$ th adapter and the origin at beginning, $N$ is the number of missiles on one rail, and $3 N$ is the number of adapter sets.

$m$ is the mass per unit length of the structure, and $E$ is the elastic modulus of the structure. The relationship between the viscous damping coefficient $c_{e}$, strain damping coefficient $c_{i}$, and the first two vertical natural frequencies of the structure $\omega_{1}$ and $\omega_{2}$, and the structure damping ratio $\xi$ is

$$
\begin{aligned}
& c_{e}=m \frac{2 \xi \omega_{1} \omega_{2}}{\omega_{1}+\omega_{2}}, \\
& c_{i}=E \frac{2 \xi}{\omega_{1}+\omega_{2}} .
\end{aligned}
$$

Assuming that the longitudinal excitation of the sliding rail to the missile is a zero-mean Gaussian random process, and according to the principle of virtual excitation method, it can be considered that the missile is affected by multipoint out-of-phase stable random excitation $\Delta z(t)$. Since the relative position of the adapters is different, $\Delta z(t)$ can be expressed as:

$$
\Delta z(t)=\left(\begin{array}{c}
\Delta z_{1}(t) \\
\Delta z_{2}(t) \\
\cdots \\
\Delta z_{t_{l}}(t) \\
\cdots \\
\Delta z_{3 N}(t)
\end{array}\right)=\left(\begin{array}{c}
\Delta z\left(t-t_{1}\right) \\
\Delta z\left(t-t_{2}\right) \\
\cdots \\
\Delta z\left(t-t_{l}\right) \\
\cdots \\
\Delta z\left(t-t_{3 N}\right)
\end{array}\right),
$$

where

$$
\begin{aligned}
l=1,2, \cdots, 3 N, & \\
t_{l} & =\frac{p_{l}-p_{1}}{v} .
\end{aligned}
$$

$t_{l}$ is the lag time between the $l$ th excitation point and the first excitation point.

Assuming that the power spectrum of the system itself is the single-sided power spectrum $S_{v}\left(k_{x}\right)$ represented by the wave number $k_{x}$ and circular frequency of time is $\Omega$ $=k_{x} v$, the single-sided power spectrum $S_{v}(\Omega)$ can be represented as

$$
S_{v}(\Omega)=\frac{S_{v}\left(k_{x}\right)}{v}
$$

If the virtual excitation of rail harmonics unevenness corresponding to $\Delta z\left(t-t_{l}\right)$ is defined as $\Delta \tilde{z}\left(t-t_{l}\right)$, then

$$
\Delta \tilde{\mathbf{z}}(t)=\left(\begin{array}{c}
e^{-i \Omega t_{1}} \\
e^{-i \Omega t_{2}} \\
\cdots \\
e^{-i \Omega t_{3 N}}
\end{array}\right) \sqrt{S_{v}(\Omega)} e^{i \Omega t}=\Delta \tilde{\mathbf{z}}(\Omega) e^{i \Omega t} .
$$

$\Delta \tilde{z}(\Omega)$ is the amplitude of the virtual excitation.

The adapters contact with the rails in linear Hertzian elastic theory; thus, the dynamic force of adapters can be obtained from displacement constraint at the contact point

$$
\tilde{F}(\Omega)=\left(A_{w}+A_{R}+A_{\Delta}\right)^{-1} \Delta \tilde{\mathbf{z}}(\Omega),
$$




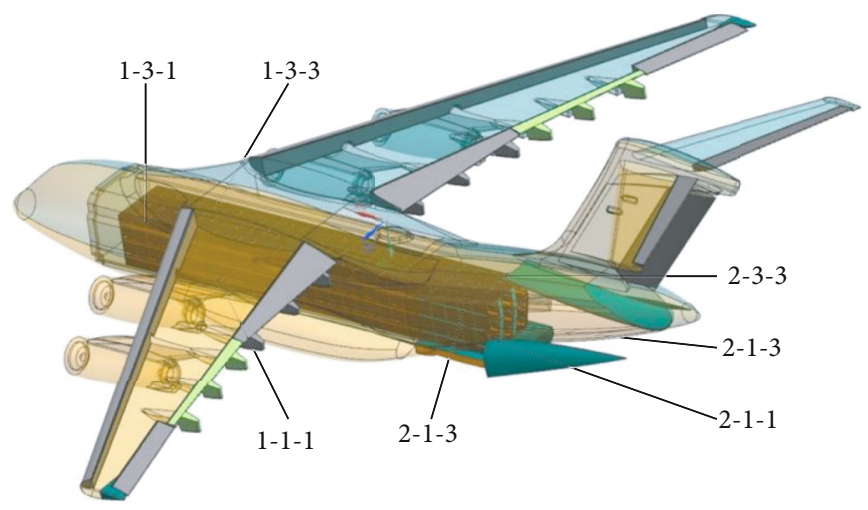

Figure 6: Examples of missile loading position labels.

where

$$
\begin{aligned}
& A_{w}=\operatorname{diag}\left(A_{w, 1}, A_{w, 2} \cdots A_{w, j}, \cdots, A_{w, N}\right) \text {, } \\
& A_{w, j}=H A_{v, j} H^{\mathrm{T}} j=1,2, \cdots, N, \\
& H=\left(0_{3 \times 6} I_{3 \times 3}\right), \\
& A_{v, j}=\left(K_{v, j}+i \Omega C_{v, j}-\Omega^{2} M_{v, j}\right)^{-1} \text {, } \\
& A_{\Delta}=\operatorname{diag}\left(\frac{1}{k_{h, 1}}, \frac{1}{k_{h, 2}}, \cdots, \frac{1}{k_{h, l}}, \cdots, \frac{1}{k_{h, 3 N}}\right) \text {, } \\
& k_{h, l}=\left(\frac{3}{2 G}\right) F_{h, l}^{1 / 3} \text {, } \\
& A_{R}=\left(\begin{array}{ccccc}
z_{r 1,1} & \cdots & z_{r 1, q} & \cdots & z_{r 1,4 N} \\
\cdots & \cdots & \cdots & \cdots & \cdots \\
z_{r s, 1} & \cdots & z_{r s, q} & \cdots & z_{r s, 3 N} \\
\cdots & \cdots & \cdots & \cdots & \cdots \\
z_{r 3 N, 1} & \cdots & z_{r 3 N, q} & \cdots & z_{r 3 N, 3 N}
\end{array}\right) \text {, } \\
& s=1,2, \cdots, 3 N q=1,2, \cdots, 3 N \text {. }
\end{aligned}
$$

$F(\Omega)$ is the virtual dynamic adapter-rail force amplitude corresponding to $\Delta \tilde{z}(\Omega) ; A_{W}$ and $A_{R}$ are, respectively, the flexibility matrix of the missile at the adapter sets and the frame at the contact point; $A_{\Delta}$ is the flexibility coefficient matrix of the adapter-rail linear Hertz contact; $A_{w, j}$ is the flexibility matrix of the $j$ th missile; $K_{v, j}, C_{v, j}$, and $M_{v}$ are the stiffness, damping, and mass matrices of the $j$ th missile, respectively; $k_{h}$ is the linear Hertz elastic contact stiffness between adapter and rail; $G$ is the deflection coefficient; $F_{h}$ is the normal force of the contact point when the wheelrail contact spring stiffness is linearized; $z_{r s, q}$ is the unit force acting on rail displacement at the sth adapter-rail contact point caused by the $q$ th adapter-rail contact point.

The power spectrum of the dynamic adapter-rail interaction force can be expressed as

$$
\mathbf{S}_{F}(\Omega)=\tilde{F}(\Omega)^{*} \cdot \tilde{F}(\Omega)^{T}
$$

TABLE 1: Experiment and FEM simulation results of missile ejection.

\begin{tabular}{lcccccc}
\hline Test Position & $\begin{array}{c}\text { Experiment/ } \\
\text { simulation }\end{array}$ & $\begin{array}{c}\text { Time } \\
(\mathrm{s})\end{array}$ & $\begin{array}{c}\text { Velocity } \\
(\mathrm{m} / \mathrm{s})\end{array}$ & $\begin{array}{c}\text { Pitch } \\
\text { angle } \\
\left({ }^{\circ}\right)\end{array}$ & $\begin{array}{c}\text { Pitch } \\
\text { angle } \\
\text { speed } \\
(\%)\end{array}$ \\
\hline \multirow{2}{*}{1} & \multirow{2}{*}{$2-1-3$} & Experiment & 0.87 & 5.77 & -3.30 & -35.30 \\
& & Simulation & 0.91 & 5.86 & -5.58 & -36.90 \\
2 & \multirow{2}{*}{$1-1-3$} & Experiment & 1.33 & 8.43 & -2.80 & -29.30 \\
& & Simulation & 1.31 & 8.99 & -3.84 & -18.50 \\
3 & \multirow{2}{*}{$1-1-1$} & Experiment & 1.2 & 9.24 & -2.30 & -29.70 \\
& & Simulation & 1.15 & 9.86 & -4.85 & -21.95 \\
4 & \multirow{2}{*}{$2-1-1$} & Experiment & 0.72 & 7.28 & -3.18 & -32.56 \\
& & Simulation & 0.74 & 7.43 & -4.52 & -20.49 \\
5 & \multirow{2}{*}{$2-3-1$} & Experiment & 0.635 & 8.44 & -3.27 & -33.79 \\
& & Simulation & 0.66 & 8.32 & -4.02 & -27.65 \\
6 & \multirow{2}{*}{$1-3-1$} & Experiment & 1.195 & 9.55 & -2.85 & -28.49 \\
& & Simulation & 1.17 & 9.79 & -3.09 & -16.62 \\
7 & \multirow{2}{*}{$1-3-3$} & Experiment & 1.05 & 10.89 & -2.45 & -23.76 \\
& & Simulation & 1.03 & 11.26 & -3.42 & -21.26 \\
\hline
\end{tabular}

Based on equation (11), virtual dynamic adapter-rail force excitation $\tilde{F}_{e}(t, \Omega)$ can be written as

$$
\tilde{F}_{e}(t, \Omega)=\sqrt{S_{F}(\Omega)} e^{i \Omega t} .
$$

Assuming that every adapter sets have the same geometric and material parameters, and the excitations they receive are completely consistent except for a fixed time difference. In this way, the distribution function $\tilde{F}_{d}(t, \Omega, x)$ of the virtual dynamic adapter-rail interaction force in the timespace domain is

$$
\tilde{F}_{d}(t, \Omega, x)=\sum_{l=1}^{4 N} \sqrt{S_{F}(\Omega)} \times e^{i \Omega\left(t-t_{l}\right)} \delta\left(x-v t-p_{l}\right) .
$$

In the frequency-wavenumber domain, equation (13) 


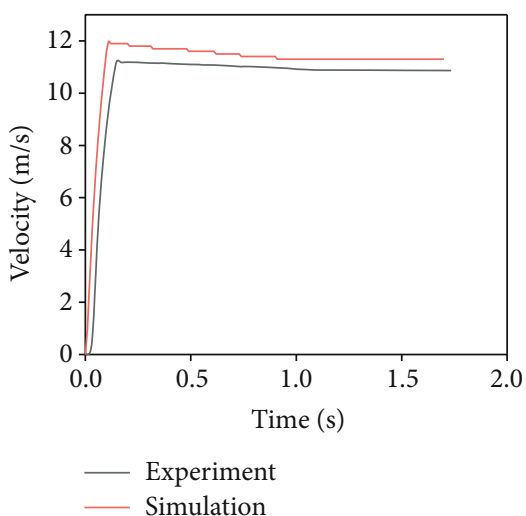

(a) Velocity

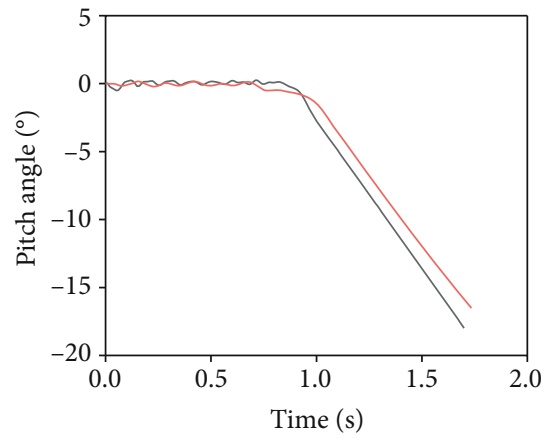

(b) Pitch angle

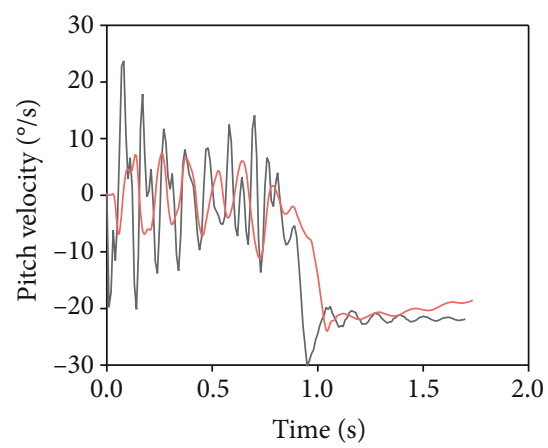

(c) Pitch velocity

Figure 7: Comparison of FEM and experiment of missile movement.

TABLE 2: The results from different simulate models.

\begin{tabular}{lccccc}
\hline Model & Time $(\mathrm{s})$ & Velocity $(\mathrm{m} / \mathrm{s})$ & Pitch angle $\left(^{\circ}\right)$ & Pitch velocity $\left({ }^{\circ} / \mathrm{s}\right)$ & $\begin{array}{c}\text { Maximum vertical displacement } \\
\text { of the frame }(\mathrm{mm})\end{array}$ \\
\hline 1 & 0.45 & 13.03 & 0.86 & 21.07 & 0 \\
2 & 0.45 & 13.1 & 0.33 & 13.38 & 0 \\
3 & 0.47 & 12.7 & 1.01 & 8.5 & 4.64 \\
\hline
\end{tabular}

can be expressed as

$\tilde{F}_{d}\left(k_{x}, \Omega, \omega\right)=\frac{2 \pi}{v} \sqrt{S_{F}(\Omega)} \times \sum_{l=1}^{4 N} e^{-i\left(\left(k_{x}+\Omega\right) / v\right) p_{l}} \delta\left(k_{x} v+\omega-\Omega\right)$.

Superimposing the launch platform's own vibration with external excitation is the vibration characteristics of the launch platform under external stimulation.

\section{Model Establishment and Verification}

In order to meet the requirements of different airborne launches, plenty of different launching systems have been proposed and had their capabilities deeply analyzed in the last few decades [17-21]. The launching method used in this article is by using a launching platform with two sets of carrier racks in the cabin of a transport aircraft. There are 9 missile units $(3 \times 3)$ in each rack, and the racks are connected by guide rails in each unit that missiles can slide on. The entire platform can carry and launch 18 missiles at a time; its structure and the layout of the launching platform are shown in Figure 3. The missiles are positioned in the guide rails through three adapter sets, each of which has four adapters, as shown in Figure 4 . The missiles are ejected by catapult device and slides on the rails. After reaching the launch speed within $2 \mathrm{~m}$, the missile maintains the speed until it leaves the launch platform and slides out of the cabin [8].

The purpose of this section is to establish a reliable finite element analysis model and to experimentally verify its computational credibility. After that, based on the requirements

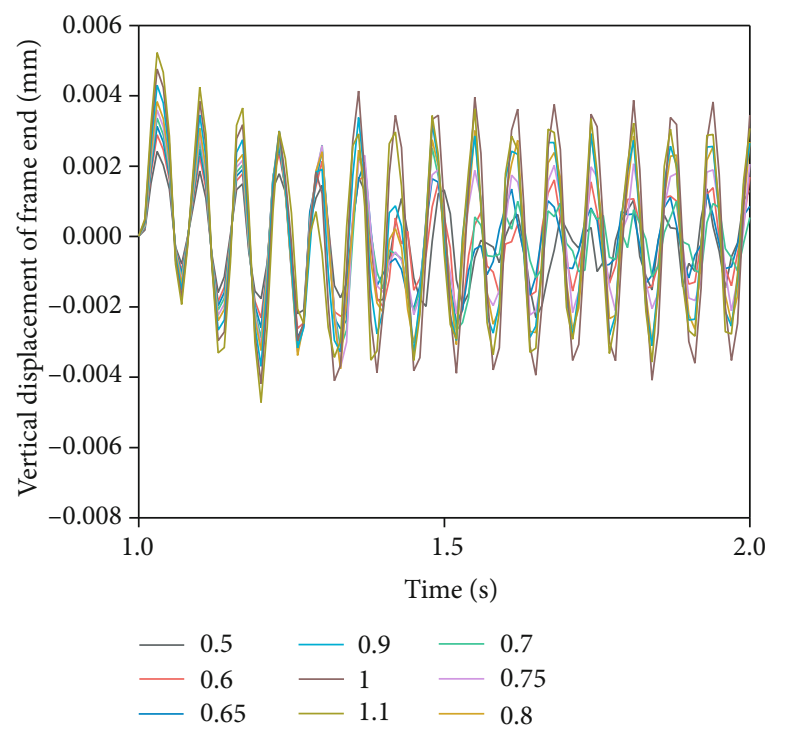

Figure 8: Vertical displacement of the frame end under different ejection force.

of simplifying the finite element model and improving the calculation efficiency, it is considered to establish two extra models that will rigidify part or all of the structure and analyze the credibility of the results. In order to verify the reliability of these models, an ejection platform was built to observe the movement of the missiles that launched backwards. A missile-carrying unit of a set of racks on the ground is shown in Figure 5.

For the convenience of expression, all the missile loading positions on the launch platform are labeled. According to the relative position between the loading position and the 


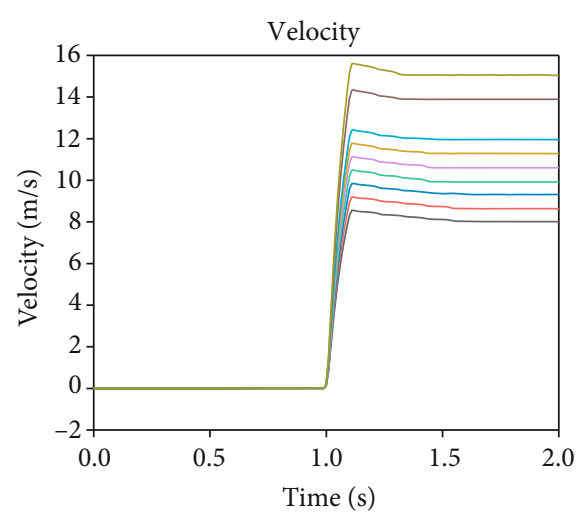

(a) Velocity

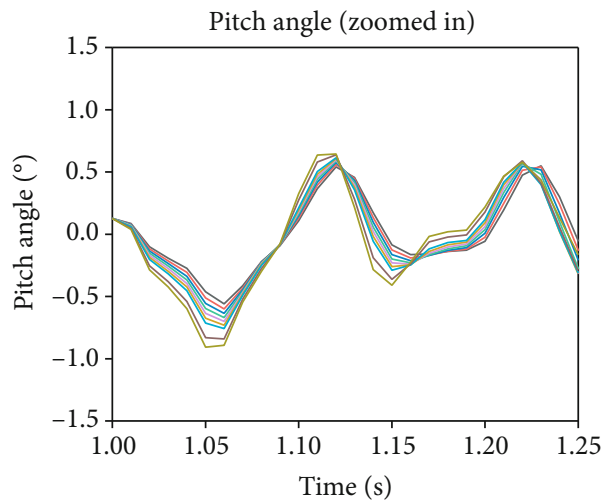

(c) Pitch angle (zoomed in)

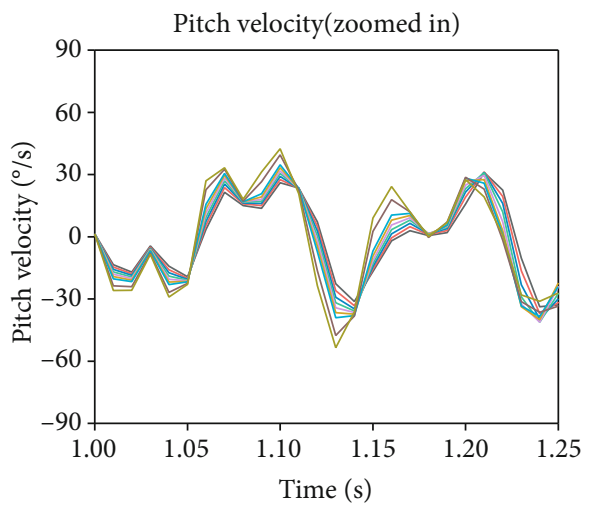

(e) Pitch velocity (zoomed in)

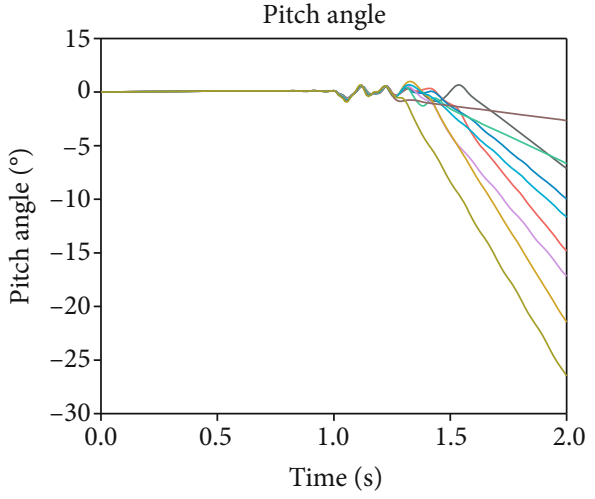

(b) Pitch angle

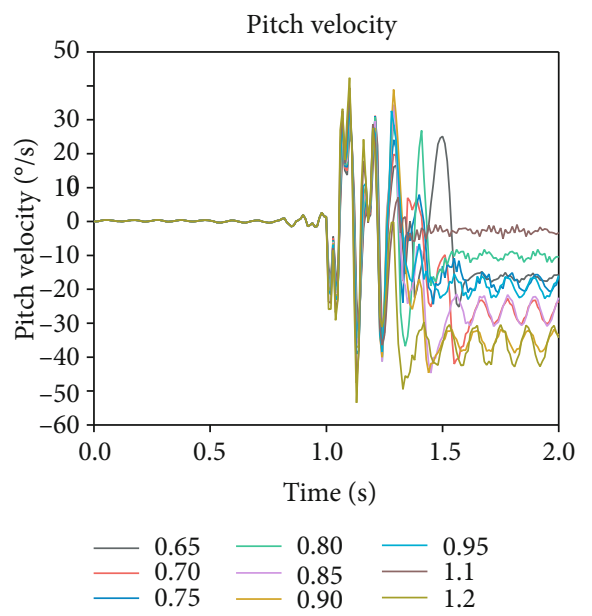

(d) Pitch velocity

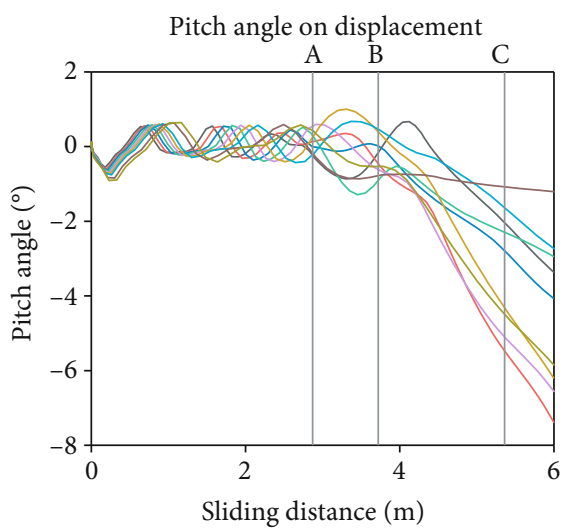

(f) Pitch angle on displacement

FIgURE 9: Comparison of missile movement under different ejection forces.

cabin, the positions are labeled as (front-rear)-(down-up)(left-right), as shown in Figure 6.

3.1. Finite Element Model and Experimental Verification. Among all the structural dynamics analytical methods, the fully flexible body structure model based on the finite element method (FEM) is analytical methods with higher accuracy and wider range of applications. In order to verify that the finite element model is accurate for dynamic simulations at all positions, seven ejection experimental tests at different positions were made and simulated in finite element model. Different ejection forces, all corresponded to the test conditions, were set as the inputs of dynamic simulation. Table 1 shows the separate time and velocity, pitch angle, pitch velocity of the missiles at separate time of simulation, and test at each position.

Due to the difference in ejection position and force, the separation time is different in each test. However, results of the FEM fit the tests very well, having minor variation between separate time and velocity from both methods. 
Pitch angle and the pitch velocity from both results are close but not same, mainly because the ejection force input to the simulation is derived from theory, which cannot fully represent the actual action of ejection process.

The curves of the missile at the position 1-1-3 are shown in Figure 7. By comparing the velocity, pitch angle, and pitch velocity curves of the missile in the simulation model and experiment, it can be found that the curves of FEM and the test are basically the same.

As shown in Figure 7, when the ejection force starts to act on the missile, its velocity increases rapidly, then decelerates due to the friction between adapters and rails, and finally leaves the guide rails. The pitch angle fluctuates at $0^{\circ}$ while missiles are sliding on the rails, affected by the vibration and deformation of the launching platform, and increases after the first set of adapters slides out of the rails, indicating the tail of missile losses the supporting from adapters. After all three sets of adapter slide out of the rails, the missile separates, and its pitch angle keeps increasing with an angular velocity of $-20 \%$ s.

The comparison of experimental and simulation results at all launching positions aggress with the above conclusions. Therefore, the simulation method using FEM in this paper is reasonable, which means the FEM results can represent the response of the missile launched backwards.

3.2. Comparison of Different Simulation Methods. According to Section 3.1, the FEM simulation is credible and can be used as a substitute model for experiments to analyze the dynamic response of the missile in the backward launch process. However, structures of the launching platform are complex, and the number of finite elements is huge. Therefore, it is considered to make part or all of the structure rigid and analysis the credibility of their simulation results.

Based on the above ideas, three simulation models were established: (1) an Adams multirigid body model, with all structures rigidized and interact directly by contact relationship; (2) a rigid-flexible coupling model in which the modalities of the rail and the adapter are imported into Adams and made flexible, and the other parts remain rigid; and (3) a fully flexible body model based on the finite element method. The separate time, velocity, pitch angle, and pitch velocity of the missile from these methods on 2-1-1 position are in Table 2.

According to Table 2,

(1) Compared with Model 2, it can be seen that Model 1 has big differences between the separate pitch angle and pitch velocity of the missile, which is mainly caused by the difference in the rigidity and flexibility of adapters, indicating that the deformation of adapters has a significant influence on the simulation results that can not to be ignored

(2) Compared with Models 1 and 2, Model 3 has a slightly lower separate velocity, indicating that the flexibility of the overall model will increase the deformation of the frame, thereby increasing the kinetic energy loss of the missile during sliding.

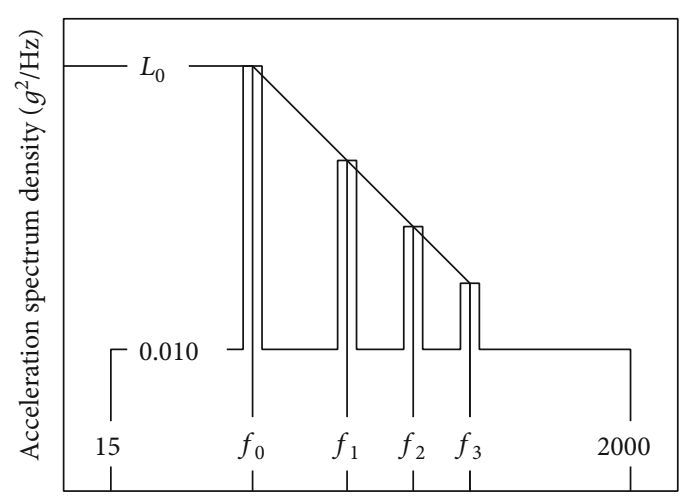

Frequency in logarithm $(\mathrm{Hz})$

FIgURE 10: Vibration power spectral density.

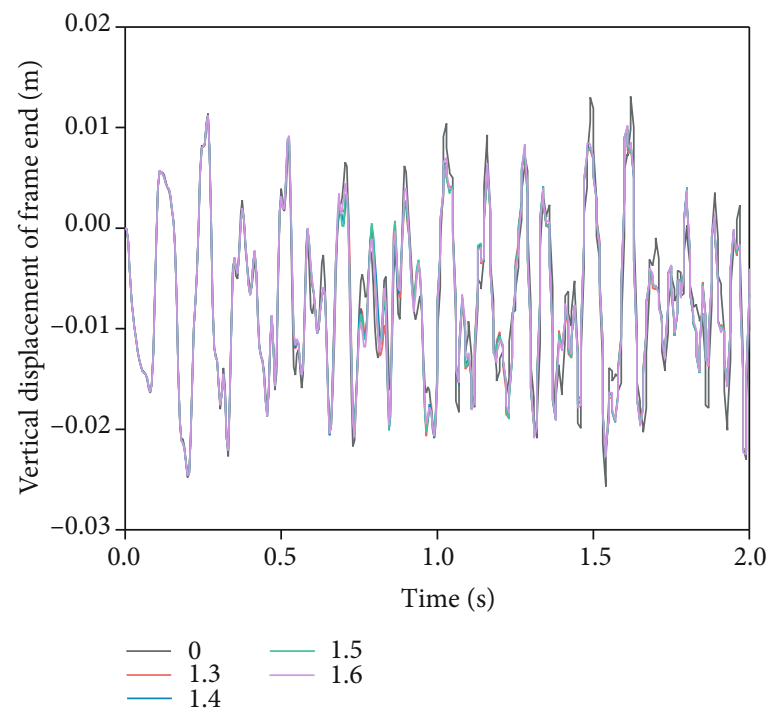

Figure 11: Vertical displacement of the frame under different ejection forces with airborne vibration.

Therefore, the rigidization of the frame will also introduce large errors, which will have a substantial impact on the results

According to the comparison of the finite element model, the rigid-flexible coupling model, and the multirigid body model, it can be concluded that during the missile launch process, the frame, rails, and adapters all vibrate and affect the ejection motion of the missile. Therefore, the use of multiple rigid bodies or rigid-flexible coupling models in the simulation model will introduce errors and affect the calculation accuracy. At the same time, FEM is still the only acceptable calculation method that can be used to replace the experimental model among the three simulation methods.

\section{The Influence of External Factors on Missile Launch}

Regarding the related studies of airborne missile horizontal backward launching methods, Pan et al. [8] studied the 


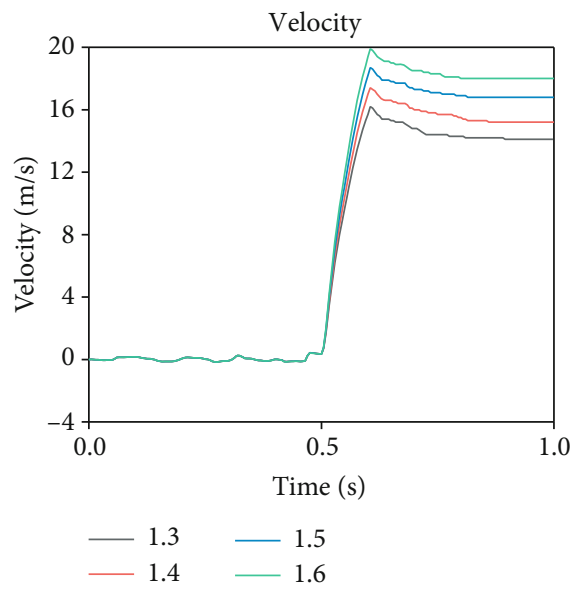

(a) Velocity

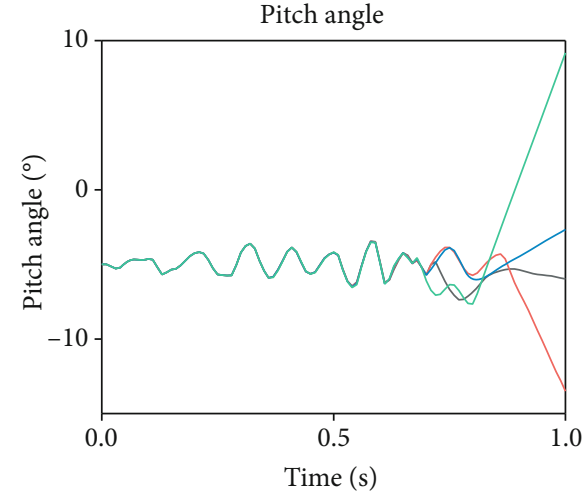

(b) Pitch angle

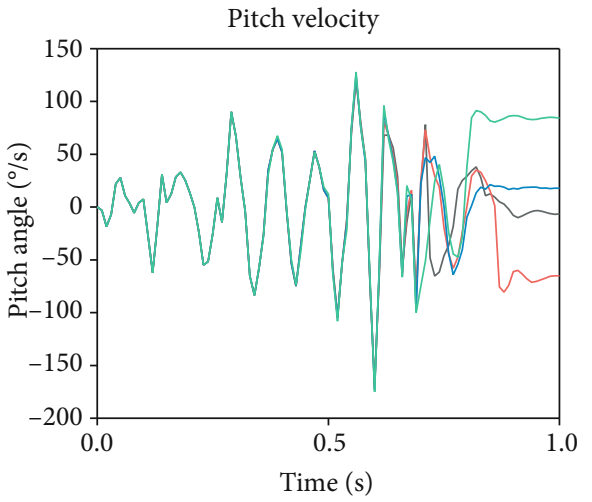

(c) Pitch velocity

FIGURE 12: Comparison of missile movement with airborne vibration.

influence of separation time and velocity of missile on the launching of the missile. Zhao et al. [1] researched the influence of external flow disturbance on missile separation trajectory. Based on the above analysis, the ejection force, the vibration of the cabin, and the position of the missile on the launch platform can also impact the motion of the missile and therefore influence the launch of the missile.

4.1. The Influence of Different Ejection Forces. In order to analyze the dynamic response of the missile ejected from the cabin backwards, the ejection force is extremely important during this process. Select $5^{\circ}$ as the initial attack angle of aircraft and a standard ejection curve multiplied with a scale factor as the input ejection forces. Figure 8 shows the curve of the vertical displacement of the frame end with time under different ejection force.

As shown in Figure 8, the period and shape of frame longitudinal vibration under different ejection forces are approximately the same, except the amplitude increases with the ejection force. Figure 9 shows the curves of missile velocity, pitch angle, and pitch velocity under different ejection forces.

As shown in Figure 9(a), since the action time of different ejection forces is the same, the relationship between missile velocity and thrust is basically linearly related, and the shape of the curve is also the same. As shown in Figures 9(c) and 9(e), before the adapter leaves the rails, the missile's pitch angle and pitch velocity fluctuate around $0^{\circ}$; the amplitude of the pitch angle and pitch velocity curve fluctuations increases slightly with the ejection force. As missiles separate earlier under larger ejection force, the pitch angle of most missiles will also increase faster after separation; some missiles do not follow to this rule because they separate at the exact moment that the adapter is being extensively compressed, resulting in a lower pitch velocity after separation.

Figure $9(\mathrm{f})$ is the curves of the pitch angle and sliding distance of the missile under different ejection forces. The curves can be divided into three parts according to the position where the adapter group is separated from the track. (1) In the first part of missile movement (before $\mathrm{A}$ in the figure), all adapters are completely constrained by the rails, with its posture mainly affected by the vibration of the launching platform and pitch angle fluctuates at the $0^{\circ}$. The distance of one vibration cycle increases with ejection force, and less vibration cycles will be performed in this part. (2) In the second part of the movement (between A and B in the figure), one-third of the missile body is not constrained. Affected by gravity and platform vibration, the adapters on the rails are compressed more firmly, and the missile pitch is also greater. 


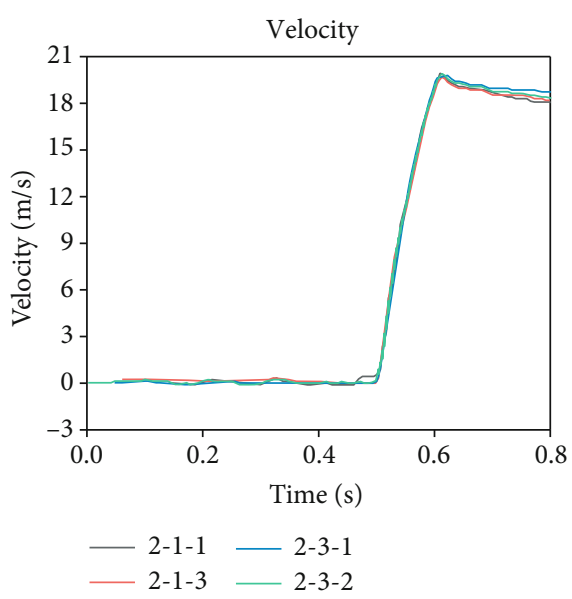

(a) Velocity

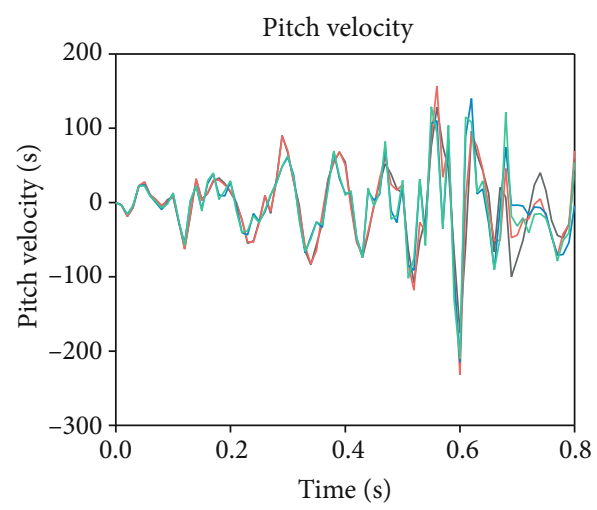

(c) Pitch velocity

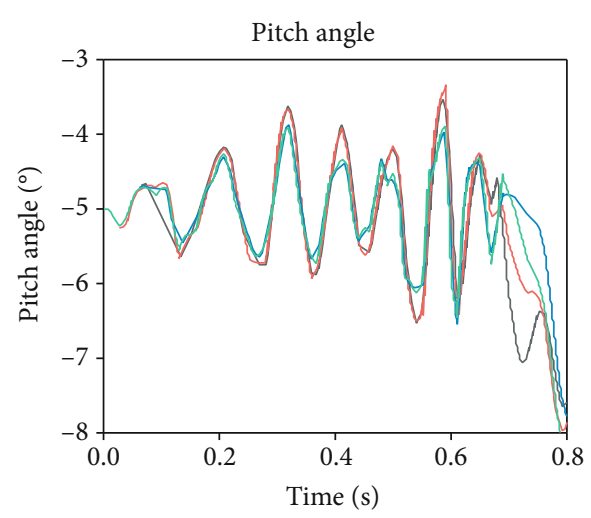

(b) Pitch angle

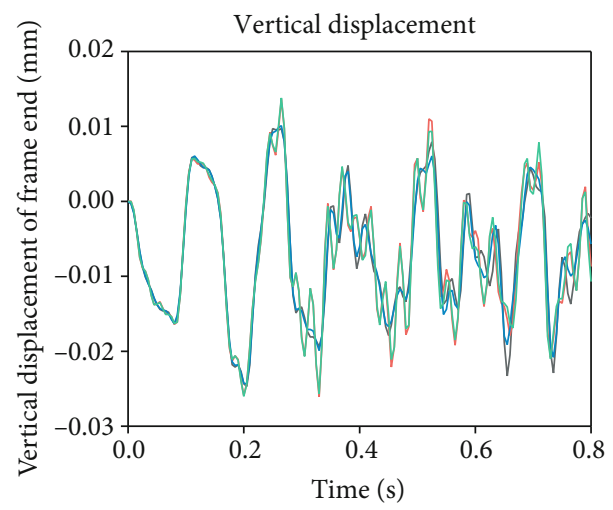

(d) Vertical displacement

FIgURE 13: Comparison of missile movement under different loading units.

TABLE 3: The results from different loading units.

\begin{tabular}{lcccc}
\hline Position & Time & Velocity & Pitch angle & Pitch velocity \\
\hline $2-1-1$ & $0.32 \mathrm{~s}$ & $18.8 \mathrm{~m} / \mathrm{s}$ & $-6.98^{\circ}$ & $68.75^{\circ} / \mathrm{s}$ \\
$2-1-3$ & $0.33 \mathrm{~s}$ & $18.2 \mathrm{~m} / \mathrm{s}$ & $-5.34^{\circ}$ & $81.52^{\circ} / \mathrm{s}$ \\
$2-3-1$ & $0.325 \mathrm{~s}$ & $18.6 \mathrm{~m} / \mathrm{s}$ & $-6.13^{\circ}$ & $65.32^{\circ} / \mathrm{s}$ \\
$2-3-3$ & $0.325 \mathrm{~s}$ & $18.3 \mathrm{~m} / \mathrm{s}$ & $-5.83^{\circ}$ & $70.47^{\circ} / \mathrm{s}$ \\
\hline
\end{tabular}

Those factors, coupled with the ejection velocity, make the pitch angle of the missile more random. (3) In the third part of the missile movement (between $\mathrm{B}$ and $\mathrm{C}$ in the figure), only one set of the adapter is constrained by the rails. At this part, the movement of missile is the same as that in Figure 9(a). (4) At this part (after C in figure), missile separates from the launching platform completely.

4.2. The Influence of Airborne Random Vibration. During the flight, the transport aircraft will generate random vibrations under its own mechanical operation and the external environment. Those vibrations would transmit to launch platform through the cabin and affect the sliding and separation of the missile. In order to study the influence of airborne random vibration on movement of the missile, a typical launch position 2-1-1 is selected for calculation. According to the standard [22], the vibration power spectral density of Figure 10 is selected as the input condition, where $L_{0}=0.3, f_{0}=68, f_{1}=136, f_{2}=204$, and $f_{3}=272$. The aircraft's angle of attack is $5^{\circ}$, and different ejection forces (including a nonforce situation) are considered. Figure 11 shows the vertical displacement of the frame end on time under different conditions.

As shown in Figure 11, the nonejection condition and the vertical displacement of the frame end under different ejection forces basically coincide, indicating that the force of the missiles to the frame under different ejection forces does not affect the frame end displacement. By comparing Figures 8 and 11, it can be found that the vibration amplitude at the end of the frame has increased by 5 times; 


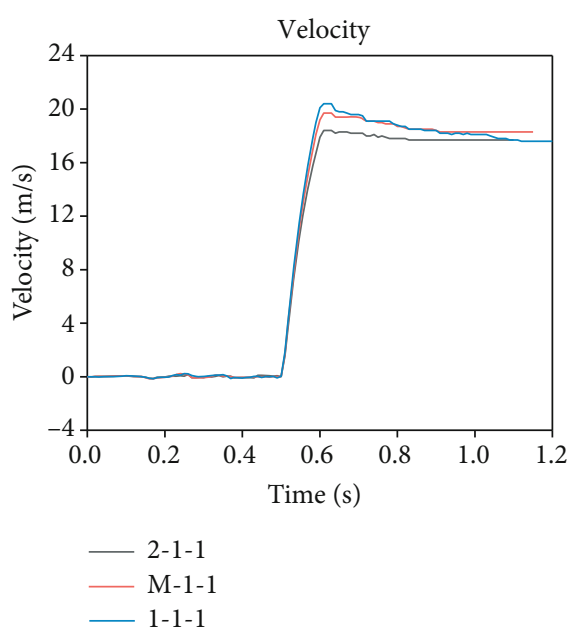

(a) Velocity

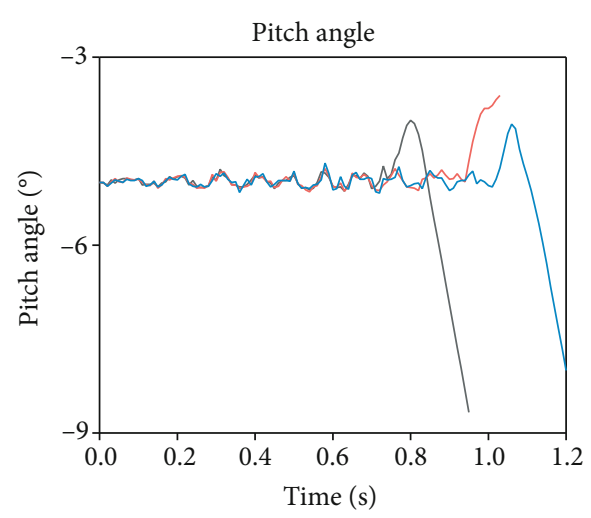

(b) Pitch angle

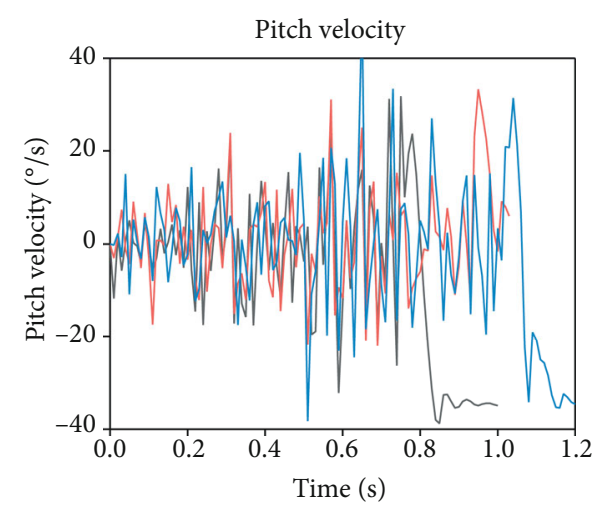

(c) Pitch velocity

FIGURE 14: Comparison of missile movement under sliding distance.

therefore, the airborne random vibration dominates the vibration of the missile frame. The missile's velocity, pitch angle, and pitch velocity under different working conditions is shown in Figure 12.

By comparing Figures 12(a) and 9(a), the velocity of missiles considering random vibration of the cabin is consistent with the velocity results without considering the vibration of the cabin. By comparing Figures 12(b) and 9(b) and Figures 12(c) and 9(d), it can be seen that when the missile is sliding on the rails, the cabin vibration has little effect on the pitch angle and pitch velocity of the missile; when the adapter sets are separated from the rails, the pressure on the remaining adapters increases, and the vibration of the missile becomes more intense, so the pitch angle and pitch velocity will also increase.

At the same time, according to the comparison of the influence of random vibration and ejection force, it can be found that the influence of random vibration on the movement of the missile is greater than the ejection force, and it also introduces randomness to the separation of the missile. Therefore, the subsequent analysis and calculation must consider the influence of random vibration.

4.3. The Influence of the Missile Launching Position. The initial position of the missile, including the unit in a rack and the sliding distance, can both affect the launching movement of the missiles.

4.3.1. The Influence of Different Loading Rack Units. In the width direction of the launching platform, the frame is subject to different constraints. For example, the middle part of the frame is connected to the outer frame, while the outer parts on both sides have no constraints. In the height direction of the launching platform, the bottom of the frame is connected with the cabin, while the uppermost frame has no constraints.

Choose 1.66 as the initial ejection force factor and $5^{\circ}$ of attack angle and launch positions 2-1-1, 2-1-3, 2-3-1, and 2-3-3 from the same rack selected; the curves of the missile's velocity, pitch angle, pitch velocity, and vertical displacement of the frame end under aircraft vibration and different loading rack units are shown in Figure 13.

As shown in Figure 13, the missile velocity, pitch angle, pitch velocity, and the vertical displacement of the frame end at four positions basically coincide. Therefore, when the launch position is in the same rack, the vibration response characteristics of the frame and the motion of the missile during the ejection at different positions are basically the same. Table 3 is the separation time, velocity, pitch angle, 
TABLE 4: The results from different sliding distance.

\begin{tabular}{lcccc}
\hline Position & Time & Velocity & Pitch angle & Pitch velocity \\
\hline $2-1-1$ & $0.32 \mathrm{~s}$ & $17.7 \mathrm{~m} / \mathrm{s}$ & $-4.85^{\circ}$ & $-37.99^{\circ} / \mathrm{s}$ \\
M-1-1 & $0.49 \mathrm{~s}$ & $18.3 \mathrm{~m} / \mathrm{s}$ & $-3.81^{\circ}$ & $2.88^{\circ} / \mathrm{s}$ \\
$1-1-1$ & $0.65 \mathrm{~s}$ & $17.6 \mathrm{~m} / \mathrm{s}$ & $-6.30^{\circ}$ & $-35.41^{\circ} / \mathrm{s}$ \\
\hline
\end{tabular}

and pitch velocity of the missile loaded in different units of a same rack.

4.3.2. The Influence of Different Sliding Distances. The sliding distance of the missile on the rails also needs to be considered for the impact of the movement of the missile during the separation. In order to analyze the trend of the impact, three initial loading locations were set on the same orbit, labeled as 2-1-1, M-1-1, and 1-1-1. M-1-1 is in the intermediate position of 2-1-1 and 1-1-1. Considering the velocity loss difference of the front, middle, and rear part of the rails, different ejection force factors $(1.48,1.58$, and 1.68) are selected in the calculation to apply the corresponding positions to ensure that the missile separate velocity is basically the same. With angle of attack of the aircraft is $5^{\circ}$ and cabin vibration considered, missile's velocity, pitch angle, pitch velocity, and the vertical displacement of the frame end with time under different working conditions are shown in Figure 14.

As shown in Figure 14(a), the speed loss during the sliding of the missile is mainly related to the sliding distance on the rails. Longer the sliding distance, greater the speed loss. As shown in Figures 14(b) and 14(c), after the ejection force begins to act, the pitch angle and pitch velocity from different position are basically the same. When the adapter starts to slide off the guide rail, the time of the missile separation is different, and the vibration state of the extension frame is affected. Therefore, the compression of the adapter is different, which may cause the weapon's separate posture to raise or lower its head. Table 4 is the separate time, velocity, pitch angle, and pitch velocity of the missile at different sliding distances.

Under the premise that the separation velocity is constant, the separation time and velocity of the missile ejection from different positions are basically the same. Different loading units with same sliding distance have little effect on the separation pitch angle and pitch velocity; but affected by structural vibration, the longer the sliding distance, the greater the amplitude of separation pitch angle and pitch velocity.

\section{Conclusion}

In this paper, by comparing the calculation results of the finite element model and experimental results, the airborne missiles horizontal backward launching calculation model using finite element method is verified. After that, the calculation results from full rigid model, partly rigid model, and finite element model are compared. Finally, based on the verified finite element model, the effect of missile ejection force, cabin vibration, and missile loading position on mis- sile separation process is analyzed, and separate time, speed, pitch angle, and pitch velocity of missile separation are studied. Through the analysis of the results, the following conclusions can be drawn:

(1) For the launching dynamics calculation of the this launching platform, the calculation results of the finite element model correspond to the results of the experiment and demonstrate that the finite element method can be used to calculate the launching process of the missile on this platform

(2) By building the finite element model, the full rigid body model, and the partial rigid body model and use these models to calculate the missile ejection performance on this launching platform, it is found that the separate time and velocity of the first two models are close to finite element model, but the pitch angle and pitch velocity on the missile separation moment are different. This is because the impact of vibration of adapters, rails, and frames on the missile motion is large and cannot be ignored. The rigid simulate methods, no matter partly or fully, are unable to simulate the vibration properties; thus, the finite element method is proved to be the only credibility calculation approach in these three models

(3) The ejection force, random vibration of the launch platform, and the loading position of the missile all affect the separation of the missile. The vibration of the launching platform will increase with the increase of the ejection force, and the random vibration caused by cabin will also increase the velocity loss of the missile when it is sliding. The loading position has little effect on the separation time and velocity of the missile. Increase of these three influencing factors will cause the increase of the separation pitch angle and pitch velocity, among which random vibration has more influence than the other two

\section{Data Availability}

The test data used to support the findings of this study are included within the article.

\section{Conflicts of Interest}

The authors declared no potential conflicts of interest with respect to the research, authorship, and/or publication of this article.

\section{References}

[1] L. Zhao, Y. Jiang, X. Wei, L. Ma, and X. Li, "Horizontal backward launch dynamics modeling and analysis," International Journal of Aerospace Engineering, vol. 2019, Article ID 4098398, 9 pages, 2019.

[2] D. h. Lee, C.-j. Kim, and S. h. Lee, "Development of unified high-fidelity flight dynamic modeling technique for 
unmanned compound aircraft," International Journal of Aerospace Engineering, vol. 2021, Article ID 5513337, 23 pages, 2021.

[3] G. Surace and M. Pandolfi, "Calculation of missile vibrations," Associazione Italiana Di Meccanica Teorica Ed Applicata, National Congress, Naples, Italy, October, 3 Milan, Associazione Italiana Di Meccanica Teorica Ed Applicata, P in Italian, 1974.

[4] S. Liao, C. Wu, and D. Ji, "Launch dynamics modeling and analysis on influencing factors for airborne missile," Journal of Projectiles, Rockets, Missiles and Guidance, vol. 33, no. 3, pp. 153-156, 2013.

[5] X. Wang, X. Rui, F. Yang, and Q. Zhou, "Launch dynamics modeling and simulation of vehicular missile system," Journal of Guidance, Control, and Dynamics, vol. 41, no. 6, pp. 13701379, 2018.

[6] Z.-S. Ma, B. Wang, X. Zhang, and Q. Ding, "Nonlinear system identification of folding fins with freeplay using direct parameter estimation," International Journal of Aerospace Engineering, vol. 2019, Article ID 3978260, 8 pages, 2019.

[7] X. Zhou, L. Wang, J. Jiang, and Z. Su, "Hypersonic aeroelastic response of elastic boundary panel based on a modified Fourier series method," International Journal of Aerospace Engineering, vol. 2019, Article ID 5164026, 13 pages, 2019.

[8] X. Pan, Y. Jiang, X. Wei, and M. Li, "Study on initial disturbance of airborne missile's horizontal backward derailment under continuous gust," International Journal of Aerospace Engineering, vol. 2019, Article ID 5620124, 10 pages, 2019.

[9] L. H. Schindel, Store Separation, ADVISORY GROUP FOR AEROSPACE RESEARCH AND DEVELOPMENT NEUILLY-SUR-SEINE, FRANCE, 1975, Technical report.

[10] E. E. Covert, "Conditions for safe separation of external stores," Journal of Aircraft, vol. 18, no. 8, pp. 624-630, 1981.

[11] H. Z. Wang, X. Li, and X. P. Wang, "Safety assessment for store separation," Aerospace Shanghai, vol. 34, no. 5, pp. 124-129, 2017.

[12] M. Chen, Y. Jiang, S. Shi, and W. Zeng, "Research on simulation method of missile adapter's separation based on combined calculation," International Journal of Aerospace Engineering, vol. 2019, Article ID 9804190, 9 pages, 2019.

[13] L. E. G. Vasconcelosde and N. P. O. Leite, Eds., "Store separation: photogrammetric solution for the static ejection test," International Journal of Aerospace Engineering, vol. 2019, Article ID 6708450, 18 pages, 2019.

[14] Y. Xu, S. Chen, and H. Zhou, "Analysis of the Magnus moment aerodynamic characteristics of rotating missiles at high altitudes," International Journal of Aerospace Engineering, vol. 2021, Article ID 6623510, 13 pages, 2021.

[15] J. Qiu and H. Ang, "Improving aileron effectiveness based on changing the position of aileron connectors," International Journal of Aerospace Engineering, vol. 2019, Article ID 5046395, 13 pages, 2019.

[16] X. Sheng, C. J. C. Jones, and D. J. Thompson, "Responses of infinite periodic structures to moving or stationary harmonic loads," Journal of Sound and Vibration, vol. 282, no. 1-2, pp. 125-149, 2005.

[17] A. P. London, L. A. Hundley, and L. J. Droppers, "Airborne rocket launch system," 2017, US Patent 9, 745, 063.

[18] Y. A. Tao, J. P. Yang, and L. R. Chai, "Actuator controller design for UAV airborne short range air-to-ground guided missile based on DSP and CPLD," DEStech Transactions on Engineering and Technology Research, 2017.

[19] J. K. Foster, T. M. Jakubowski Jr., and R. Binkholder, "Multiple missile and bomb carriage system," 2017, US Patent App. 15/068, 304.

[20] R. Webster, D. G. Hyams, and K. Sreenivas, "Unstructured grid technology applied to axial-flow compressors," in 48th AIAA Aerospace Sciences Meeting Including the New Horizons Forum and Aerospace Exposition, Orlando, Florida, 2013.

[21] W. Schiehlen, "Multibody system dynamics: roots and perspectives," Multibody System Dynamics, vol. 1, no. 2, pp. 149-188, 1997.

[22] 25-R3 C, “Test standard for transport aircrafts," 2011. 